\title{
Correction to: Flat-panel CT arthrography for cartilage defect detection in the ankle joint: first results in vivo
}

\author{
Sarah Pagliano ${ }^{1,2} \cdot$ David Chemouni $^{1} \cdot$ Roman Guggenberger ${ }^{3} \cdot$ Vanessa Pauly $^{4} \cdot$ Daphné Guenoun ${ }^{1,2}$. \\ Pierre Champsaur ${ }^{1,2} \cdot$ Thomas Le Corroller ${ }^{1,2}$
}

Published online: 20 March 2020

(C) ISS 2020

\section{Correction to: Skeletal Radiology.} https://doi.org/10.1007/s00256-020-03398-9

The names of the following authors were inadvertently inverted in the original manuscript. The correct names are given below:

Sarah Pagliano

David Chemouni

Roman Guggenberger

Vanessa Pauly

Daphné Guenoun

Pierre Champsaur

The original article has been corrected.

Publisher's note Springer Nature remains neutral with regard to jurisdictional claims in published maps and institutional affiliations.

The online version of the original article can be found at https://doi.org/ 10.1007/s00256-020-03398-9

Thomas Le Corroller

Thomas.LeCorroller@ap-hm.fr

1 Radiology Department, APHM, Marseille, France

2 CNRS, ISM UMR 7287, Aix-Marseille Université, Marseille, France

3 Institute of Diagnostic and Interventional Radiology, University Hospital Zurich, Ramistrasse 100, 8091 Zurich, Switzerland

4 Unité de Recherche EA3279, Santé Publique et Maladies, Chroniques: Qualité de vie Concepts, Usages et Limites, Déterminants, Aix-Marseille Université, Marseille, France 